\title{
Sobre la posibilidad de alegar la inexistencia de un acto por vía de acción (Corte de Apelaciones de Chillán)
}

\author{
Comentario de Nathalie Walker Silva*
}

Chillán, dos de marzo de dos mil quince.

VISTO:

\section{EN CUANTO A LA OBJECión DE DOCUMENTOS:}

PRIMERO: Que, a fojas 780, don Edmundo Von Pottstock Molina por la parte recurrente, impugna los documentos acompañados por la parte recurrida (la demandante), por falta de integridad, falta de autenticidad y/o falsedad. Respecto de los documentos relativos al Lote $\mathrm{N}^{\circ} 1$ señalados a fojas 773 en el acápite $\mathrm{N}^{\circ} 1$ (UNO), la recurrente mencionada los objeta en virtud de lo establecido en el artículo $346 \mathrm{~N}^{\circ} 3$ del Código de Procedimiento Civil, por falta de integridad y/o falsedad, al ser simples copias sin haber sido validadas ante Ministro de Fe o terceros, ni confrontada por otros medios de prueba de acuerdo con lo establecido en los artículos 1.702 y 1.706 del Código Civil, no pudiendo hacer fe de la verdad de lo contenido en ellos. Expresa que su contenido resulta poco objetivo, especulativo e intenta engañar al Tribunal en un acto de completa mala fe. Respecto de los antecedentes relativos a los Lotes A y D señalados a fojas 774 en los acápites Dos y Tres, la recurrente los objeta en virtud de lo establecido en el artículo 346 número 3 del Código de Procedimiento Civil, por falta de integridad y/o falsedad al ser simples copias, sin haber sido validados ante Ministro de Fe o terceros, ni confrontada por otros medios de prueba de acuerdo con lo establecido en los artículos 1.702 y 1.706 del Código Civil, no pudiendo hacer fe respecto de la verdad de lo contenido en ellos. En síntesis, señala que su contenido resulta poco objetivo, especulativo e intenta engañar al Tribunal, en un acto de completa falta de fe. SEGUNDO: Que, como puede apreciarse, amen de no invocar hecho alguno constitutivo de falta de integridad o de falsedad respecto de los documentos objetados, es del caso tener presente que, de la fundamentación expuesta en el motivo precedente, se puede observar que lo que en definitiva se ha impugnado respecto de dichos documentos es el valor

* Abogada, Licenciada en Derecho, Magíster en Ciencia Jurídica y Doctoranda del Programa de Doctorado en Derecho de la Pontificia Universidad Católica de Chile. Profesora de Derecho Procesal, Pontificia Universidad Católica de Chile y Universidad Bernardo O’Higgins. Becaria Conicyt. Correo electrónico: nwalker@uc.cl 
probatorio de ellos, circunstancia que en nuestro derecho procesal es inadmisible pues, la facultad exclusiva y excluyente de dar o no valor probatorio a la prueba rendida solo corresponde al Tribunal y no a las partes litigantes. Así las cosas, la impugnación formulada a fojas 780 , será rechazada.

\section{EN CUANTO AL FONDO:}

VISTO: Se reproduce la sentencia en alzada de diez de noviembre de dos mil catorce, escrita a fojas 576 y siguientes, con excepción de sus fundamentos 9. y 10. que se eliminan. En el fundamento 6. se elimina toda la oración final, cuyo texto es el siguiente: "Con ello se concluye que no existe la denominada comunidad o condominio denominado Villa Del Bosque Nevado compuesta por los edificios Los Alerces, Los Coigues, Los Mañíos, Los Ñirres, Los Pangues y Los Robles”. Y en su lugar se tiene, además, presente: PRIMERO: Que, se puede definir la inexistencia como la sanción que tienen los actos celebrados con omisión de uno de los requisitos exigidos para la existencia jurídica. En otros términos, el acto es inexistente cuando falta el consentimiento, el objeto, la causa o las solemnidades establecidas para la existencia del acto. SEGUNDO: Que, como primera cuestión y para un mejor acierto del fallo es necesario tener presente que, la tesis de la inexistencia del acto jurídico es ajena a nuestro derecho, sistema legislativo y, en particular, al Código Civil, que no la establece como causal de ineficacia, señalando en cambio otra sanción, y esta es precisamente la nulidad, para los casos de omisión de requisitos que la ley prescribe para la existencia de ciertos actos. Por consiguiente, carece de fundamento la petición en orden a declarar la inexistencia del acto jurídico cuestionado en estos autos. TERCERO: Que, sin perjuicio de lo dicho precedentemente, de admitirse la inexistencia en nuestro derecho, es del caso tener presente que si bien es cierto, la nulidad puede alegarse como acción o excepción, la inexistencia solo puede serlo por vía de excepción. La acción de nulidad de un acto puede constituir el objeto del juicio, mientras que ninguna acción existe para hacer declarar la inexistencia del acto. El acto inexistente, en efecto, equivale a la nada, y por lo tanto, no es posible que la nada pueda ser objeto de una acción y, por lo tanto, tampoco puede constituir materia de un juicio. CUARTO: Que, teniendo presente lo razonado precedentemente, la acción deducida a fojas 1 en estos autos, no puede prosperar. Por estos fundamentos y lo dispuesto en los artículos 186 y 227 del Código de Procedimiento Civil, se declara: I. En cuanto a la objeción de documentos: Se rechaza la objeción de documentos formulada a fojas 780, por don Edmundo Von Pottstock Molina. II. En cuanto al fondo: Que, se revoca la sentencia apelada de diez de noviembre de dos mil catorce escrita de fojas 576 a 587, que declaró inexistente el Comité de Administración de la Villa Bosque Nevado conformado por los demandados, y en su lugar se declara, que no se hace lugar a la demanda de fojas 1 interpuesta en lo principal. Que, no se condena en costas al demandante, por tener motivos plausibles para litigar. Regístrese y, en su oportunidad, devuélvase. Redacción a cargo del Ministro señor Christian Hansen Kaulen. No firma el Ministro señor Arias Córdova, 
no obstante haber concurrido a la vista de la causa y al acuerdo, por encontrarse ausente, haciendo uso de feriado. Se deja constancia que el presente fallo se expide con esta fecha, por haber hecho uso de la facultad contemplada en el artículo 82 del Código Orgánico de Tribunales el Ministro señor Hansen Kaulen. R.I.C.: 872014 Crimen. Pronunciada por el Ministro señor Christian Hansen Kaulen, Presidente Subrogante, el Ministro señor Claudio Arias Córdova y el Fiscal Judicial señor Solón Vigueras Seguel. Autoriza la Secretaria Subrogante señora Miriam Contreras Fuentes. En Chillán, a dos de marzo de dos mil quince, notifiqué en Secretaría por el Estado Diario, la resolución precedente y la de fojas 792 .

\section{COMENTARio}

La sentencia que hemos escogido comentar nos ha parecido destacable por haberse pronunciado negativamente acerca de la posibilidad de alegar la inexistencia de un acto por vía de acción. Y, de modo aún más específico, niega la viabilidad del ejercicio de una acción meramente declarativa de inexistencia.

El fallo en comento nos obliga a remontarnos a una discusión de larga data en Derecho Civil, que intenta responder las preguntas asociadas a la utilidad -y necesidadde distinguir entre nulidad absoluta e inexistencia de los actos. Tal discusión tiene sus orígenes más remotos en el trabajo de los canonistas medievales, quienes partían de hipótesis para las cuales la ley no había dispuesto la nulidad, y, en las que, sin embargo, era absurdo sostener que el acto era válido por aplicación de la vieja máxima que postulaba que no había nulidad sin texto expreso de la ley. Más tarde, la doctrina francesa clásica la aplicó al caso de ausencia de consentimiento matrimonial, a la falta de consentimiento en los contratos y con posterioridad, en general, a la carencia de requisitos esenciales ${ }^{1}$. Nuestro país ha replicado esa discusión con tintes propios y con una clásica disputa entre dos grandes juristas del Derecho Civil: Arturo Alessandri Rodríguez y Luis Claro Solar; afirmando el primero que la máxima sanción de ineficacia de un acto contemplada por nuestro ordenamiento es la nulidad absoluta, versus la tesis del segundo, que pone en ese sitial a la inexistencia.

Sin grandes elucubraciones, la Corte de Chillán arriba a una conclusión tan categórica como, a juicio nuestro, acertada: "la tesis de la inexistencia del acto jurídico es ajena a nuestro Derecho, sistema legislativo y, en particular, al Código Civil, que no la establece como causal de ineficacia, señalando en cambio otra sanción, y esta es precisamente la nulidad, para los casos de omisión de requisitos que la ley prescribe para la existencia de ciertos actos. Por consiguiente, carece de fundamento la petición en orden a declarar la inexistencia del acto jurídico cuestionado en estos autos”. Acto seguido, declara que: "de admitirse la inexistencia en nuestro derecho, es del caso tener presente que si bien

\footnotetext{
${ }^{1}$ Alberruche Díaz-Flores, $\mathrm{M}^{\mathrm{a}}$ Mercedes, La rescisión por lesión en el Derecho español, Editorial La Ley,
} Madrid, p. 93. 
es cierto la nulidad puede alegarse como acción o excepción, la inexistencia solo puede serlo por vía de excepción. La acción de nulidad de un acto puede constituir el objeto del juicio, mientras que ninguna acción existe para hacer declarar la inexistencia del acto".

Efectivamente, consideramos que el pronunciamiento de la Corte es acertado, ya que del examen de las normas del Código Civil y de las fuentes utilizadas por Bello para la redacción del Código Civil es posible concluir dos cosas en ese ámbito: primero, que la inexistencia no fue contemplada por el Código como un tipo de ineficacia distinto a la nulidad absoluta y, segundo, que para Bello no fue ajena la discusión doctrinaria de los autores franceses en torno a la viabilidad de concebir la inexistencia como una clase autónoma de ineficacia. Las fuentes del Código Civil chileno explicitan esa discusión, la que Bello no pudo menos que valorar y de ningún modo ignorar.

Lo anterior nos lleva a concluir que hay un afán deliberado del redactor del Código Civil en torno a considerar la nulidad absoluta como máxima sanción, evitando con ello, precisamente, trasplantar a nuestro ordenamiento la eterna $-\mathrm{y}$ no siempre fecunda- discusión en torno a los requisitos de existencia y validez de los actos jurídicos.

En uno de los vistos de la sentencia, la Corte señala que "el acto inexistente, en efecto, equivale a la nada, y por lo tanto, no es posible que la nada pueda ser objeto de una acción y, por lo tanto, tampoco puede constituir materia de un juicio". De esa manera, la Corte pone énfasis en un punto esencial: la inexistencia es un concepto que transita por el terreno de lo puramente fáctico, mientras que la nulidad sí es un concepto propiamente jurídico. Así, el conflicto jurídico solo se planteará cuando una parte alegue acerca de las supuestas obligaciones emanadas de un acto que ella considera existente, siendo al demandado a quien corresponderá alegar la falta de requisitos que la ley prescribe para la validez de dicho acto en atención a su naturaleza -inexistencia del acto, si se quiere-, mediante una excepción perentoria. Sostener que el demandante puede sustentar su acción en la falta de existencia del acto, implicaría partir del supuesto de postular "la nada" como causa de pedir, tal como se desprende de lo expuesto en la sentencia. 